\title{
Integrating leprosy control into primary health care: the experience in Ghana
}

\author{
KOBINA ATTA BAINSON \\ Ankaful Leprosy Hospital, P.O. Box A99, Cape Coast, Ghana
}

\author{
Accepted for publication 14 March 1994
}

\begin{abstract}
Summary Integration of leprosy control into primary health care is the most comprehensive and permanent system of delivering care to leprosy patients. But so far only a few countries have adopted this approach, largely on account of a fear of failure.

Over the past decade Ghana has developed a model approach towards the transition from a vertical to an integrated programme. The highlights of our approach included the development of the leprosy service as part of the overall development of the health service, increasing capacity building for leprosy control at the district and subdistrict levels as well as the establishment of a regular and effective monitoring to identify and correct operational problems early.

This paper describes the principles behind the integration, the strategies adopted and how they were implemented. It also includes the achievements made as well as the problems that were encountered and how they were solved.
\end{abstract}

\section{Introduction}

The Ghana Leprosy Service has developed a model approach towards the integration of leprosy control into the mainstream primary health care programme. For most of the decade this new initiative has been in existence the programme has recorded a number of successes. During this period much experience has been gained in tackling the problems that accompany the transition from a vertical to an integrated programme. It is hoped that countries that have not yet taken the initiative towards integration and those which have already implemented this will benefit from these experiences.

\section{Background information}

Ghana lies along the west coast of Africa. It is bounded by 3 francophone countries: Burkina Faso to the north, Côte d'Ivoire to the West and the Republic of Togo to the east. The country covers an area of 238,533 square kilometres.

The estimated total population in 1993 was 16 million. A little over $60 \%$ of these live in the rural areas and $46 \%$ are children aged under 15 years. The annual per capita income is US $\$ 400$ and the doctor/population ratio is $1: 12,500$. 


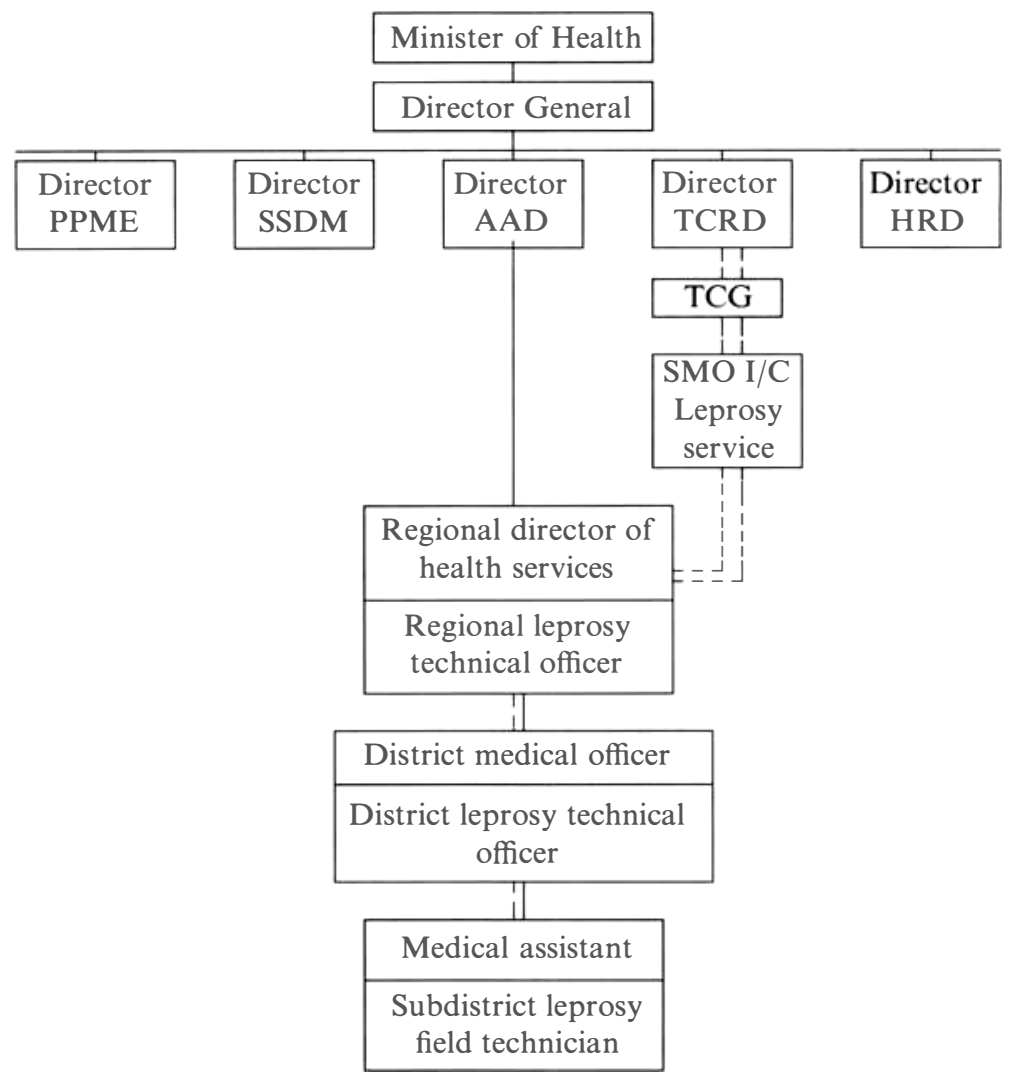

- - - Line of technical supervision in the region. - Line of administrative supervision. $====$ Line of technical supervision at headquarters. PPME; Policy planning monitoring and evaluation; SSDM; Stores, supplies and drug management; AAD; Accounts and administration division; TCRD; Technical coordination and research division; HRD; Human resource division; TCG; Technical coordination group.

Figure 1. Structure of the Ministry of Health showing the new line of management of the leprosy service.

Administratively there are 10 regions with 110 districts; at the national level the country is governed by an elected government. In line with the decentralization policy the role of the districts has been strengthened by the creation of a district assembly. The assembly is made up of the executive and legislative wings. The latter comprises representatives from various constituencies in the district. Thus the district assembly is responsible for the overall development of the district, including formulation of programmes, strategies and resource mobilization.

\section{Ministry of Health}

The Ministry of Health has undergone considerable organizational change in recent 
times. The primary objective of these changes has not only been the decentralization of the health service but also to make services more effective and efficient. The current structure of the ministry is illustrated in Figure 1.

Under the current structure the former posts of Principal Secretary and Director of Medical Services have been combined in the Director-General of Health Services, who is responsible for the overall management and technical direction of Ministry of Health activities.

In the current structure the Director-General is directly served by 5 directors: Director for Accounts and Administration Division (AAD), Director for Policy Planning, Monitoring and Evaluation (PPME), Director for Technical Coordination and Research Division (TCRD), Director for Human Resource Division (HRD) and Director for Supplies, Stores and Drug Management (SSDM).

Each region is headed by the Regional Director of Health Services (RDHS), who is responsible directly to the Director-General. The district health team is headed by the District Medical Officer who is responsible to the Regional Director for Health Services.

\section{Leprosy Control Programme}

The Ghana Leprosy Control Programme has been in existence since the late 1940s. From the onset, the programme was run vertically with its headquarters at the Ankaful Leprosy Hospital, which is about $150 \mathrm{~km}$ from the capital, Accra. There are 4 leprosy hospitals.

Under the vertical programme the administrative and technical aspects of the programme were the direct responsibility of the Senior Medical Officer in charge of the programme. With integration, many of these functions have been devolved to the regional, district and subdistrict levels. The prime responsibilities of the headquarters are now:

to assist in the development of national policies related to leprosy control;

to monitor and evaluate regional programmes and give technical advice and support where necessary;

to liaise between the Minister of Health and donors on the type and level of support needed, as well as channel donor support to the regions; and

to develop health education materials on leprosy as well as train trainers in the regions in leprosy control.

The prevalence of leprosy has decreased from over 20,000 in 1983 to 2,155 in 1993. This gives a current national prevalence rate of $1 \cdot 4$ per 10,000 . The case detection rate fell from a level of 20 per 100,000 to 10 per 100,000 in 1988. Since then this level has been maintained. The proportion of new patients with disability grade 2 stands at $5 \%$.

Multidrug therapy (MDT) was introduced in 1984 and 100\% MDT coverage was achieved in 1991.

\section{Events leading to integration}

In Ghana, a number of events necessitated the integration of leprosy control into the mainstream health care. These were: 
In 1978, the Alma Ata Conference ushered in the primary health care concept. This concept was embraced wholeheartedly by Ghana. However, to fully implement the programme, it became necessary to reorganize the ministry structurally and functionally. The resulting changes effectively abolished the vertical programme, because many of their functions were devolved to the district, subdistrict and regional levels.

In 1981 the ministry stopped the training of specialized leprosy technical officers. The training of multipurpose technical officers for epidemiology had started, so it became unnecessary to continue training officers solely for leprosy control.

In the early 1980s the country suffered its severest setback in its balance of payments. Resources for health programmes were severely curtailed, thus bringing to light the inefficiency of the vertical programmes. It was, therefore, anticipated that unless alternative approaches were adopted to control leprosy, the programme could suffer a severe setback.

\section{Principles behind integration}

The approaches that we adopted towards the integration of leprosy control were founded on the following principles. First, leprosy control is an integral component of the health service. Consequently, the changes that are made in the leprosy service should keep pace with changes in the health service as a whole. Secondly, regions have different health care needs and resources, different levels of health care development as well as different sociocultural environment and geography. Therefore, for activities which could be severely hindered by some of these factors, it is essential that some regions be allowed to move along at a slightly slower pace.

\section{Laying the foundation}

For the effective implementation of primary health care it is essential to develop the health service at district level. It was recognized that the basic unit for health planning, budgeting and management was the administrative district, and all components of health work should be fully coordinated at district level.

In this regard, since the mid-1980s, a number of initiatives have been introduced by the ministry which have strengthened health care management at district level. These included:

the appointment of substantive district medical officers who would be responsible for the overall management of health programmes in the districts;

the creation of the district health management teams made up of the heads of health programmes and other health-related agencies;

strengthening capacity building at the district level. This included management courses for all members of the district health management teams;

strengthening logistical support to districts, especially the provision of transport for health activities;

introduction of management information systems for monitoring and evaluating performance as well as developing policies; and

training in health systems research for members of the district health management teams. 
The first 2 digits, which range from 1 to 10 , identify the regions, which are coded in alphabetical order.

The next 2 digits - i.e. the 3 rd and 4th-identify a particular district; they range from 1 to 18 , according to the number of districts in each region. Again, the districts are coded in alphabetical order.

The fifth digit identifies the health facility in the district, where a leprosy patient goes to receive anti-leprosy drugs. The coding is done according to whether there are leprosy patients within the catchment areas of the health facility. This digit ranges from 1 to 9 , as there is no district with more than 9 recognized government health facilities.

The last 3 digits identify the patient.

\section{Ghana Leprosy Service, Ministry of Health, Epidemiology Division}

Leprosy Treatment Register, Region

About the registration numbers:

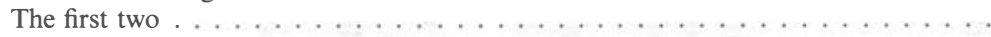

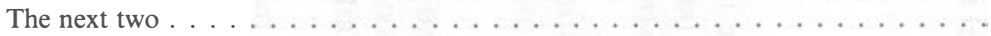

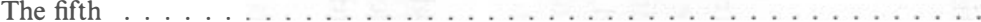

The last three digits

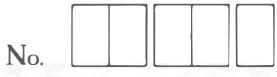

DISTRICT

YEAR

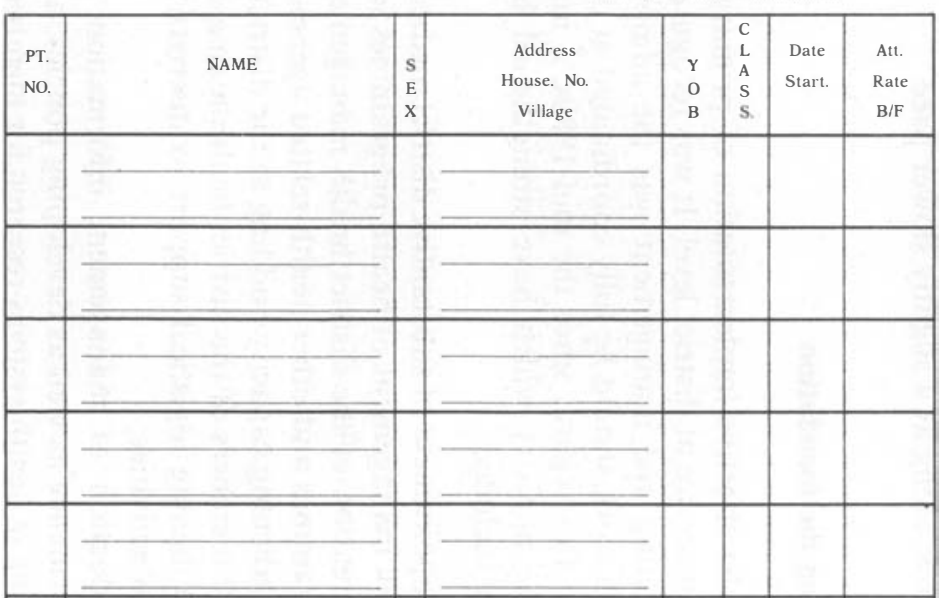

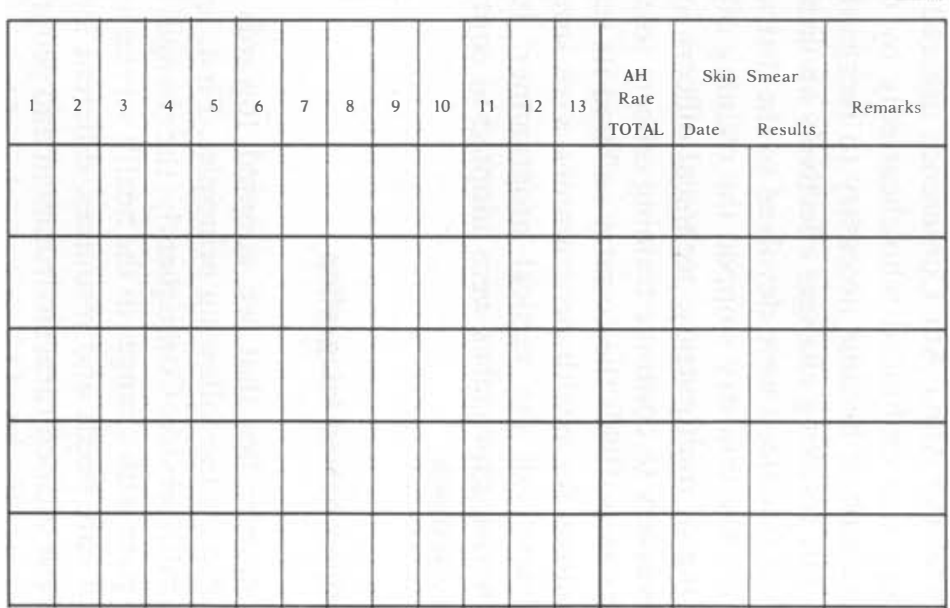

Figure 2. 


\section{Implementation}

The foundation for integration having been laid at the district level, the next task was the devolution of some of the functions of the headquarters of the leprosy service. To ensure a smooth transition, however, it was necessary that it was done in phases.

In the first phase, the administrative functions of the programme were devolved to the regions. This in effect meant that regions were made responsible for supply of fuel for leprosy programmes, staff salaries and promotion, discipline of staff, etc.

In the second phase the main area of emphasis was the preparation of health care managers and providers for the technical management of leprosy control within their respective regions. It was recognized that most health care managers and providers were not so well versed in leprosy control as to be capable of managing the disease within their areas of operation. Consequently, it became necessary to conduct training in leprosy control for all health workers whose duties were directly related to leprosy control.

The training focused on 4 key areas:

Training of trainers in health training institutions. Currently, leprosy control has been incorporated in the curricula of all health training institutions, including medical schools.

Training of health care managers in leprosy control. Training has been organized for Senior Medical Officers in charge of public health in the regions as well as members of district health management teams.

Training of health care providers at the subdistrict level. A manual had been developed specif ying the roles each category of health worker would play in leprosy control as well as the knowledge and skill required to perform such roles. The staff who were selected for such training included Medical Assistants, Public Health Nurses, Community Health Nurses, Health Inspecting Assistants and Epidemiology Technical Officers.

Training of members of the Regional Training Units. The training was arranged so that the regional training units trained the District Health Management Teams, who in turn trained the subdistrict staff.

In the third phase of integration the focus has been the gradual devolution of some specific functions to the district and subdistrict level, clarification of the roles of specialized leprosy technical officers vis-à-vis 'non-specialized' leprosy care providers as well as a systematic monitoring and evaluation of regional, district and subdistrict programmes.

The first task which was devolved at the subdistrict level was the administration of antileprosy drugs. To assist record-keeping, however, a simple treatment card was designed for the health centres (Figure 2). Subsequently, these roles have been broadened to include the diagnosis of leprosy, health education, case-finding, caseholding, surveillance, and medical care. Because most Medical Assistants have not yet become fully competent in the diagnosis of leprosy, currently all suspected cases have to be confirmed by the district leprosy technical officers. In due course, however, patients will receive their treatment on the same day they are diagnosed at the health centre.

In the final phase, which has commenced in 1994, the emphasis is to increase the capacity of district hospitals to recognize and manage the complications of leprosy. With the current low bed occupancy of all the leprosy hospitals, a decision has been taken to admit general cases into all leprosy hospitals.

The role of the leprosy technical officer has been the drawing of district action plans 


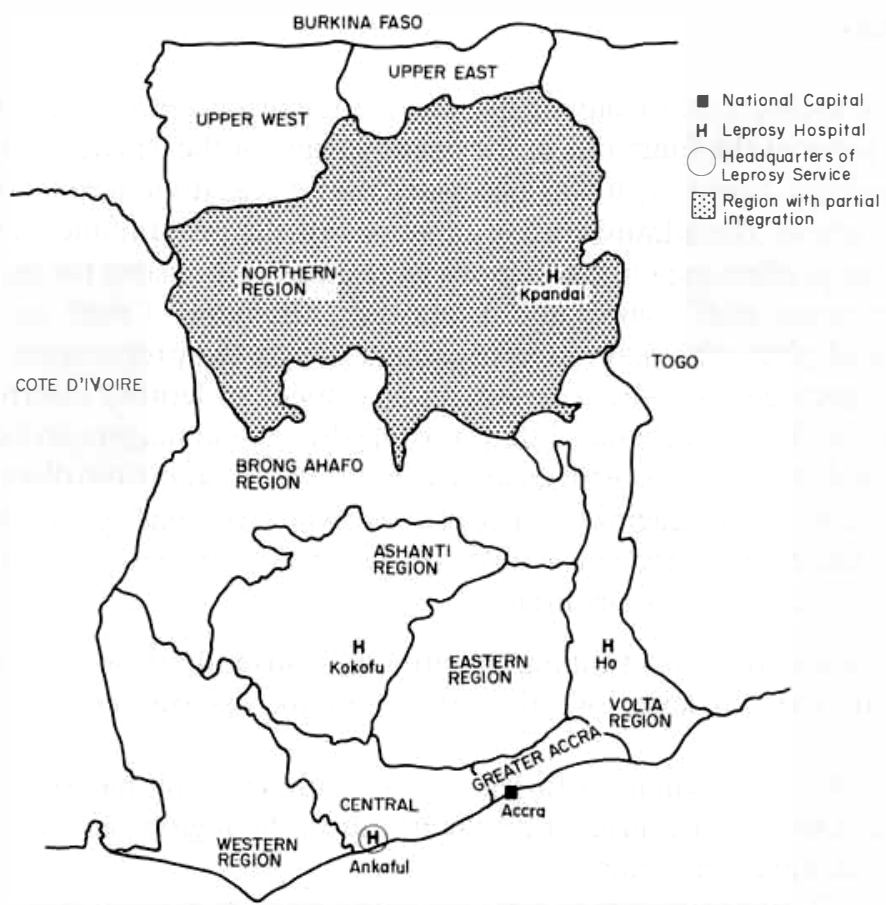

Figure 3.

for leprosy control, supervision of subdistrict staff, confirmation of diagnosis, performance of VMT \& ST, record-keeping, supply of antileprosy drugs and footwear, slit-skin smear, etc.

\section{Monitoring and evaluation}

During the transition phase towards full integration it is critical that an effective monitoring system be established to identify and promptly correct operational problems which may arise in the implementation of the programme. Unless regions, districts and subdistricts are given regular feedback on their performance all efforts made will be frustrated.

The headquarters monitors the regions twice a year, the regional technical officer monitors each district once every quarter and the district technical officer monitors each subdistrict once a month. A checklist was designed at the headquarters and regular feedback is given.

\section{Achievements}

There have been a number of achievements since leprosy control was integrated into the mainstream health care: 
Treatment for leprosy patients has been established in all health facilities and is administered by Medical Assistants. Currently most leprosy patients receive their drugs within $8 \mathrm{~km}$ of a health facility.

In total, 9 out of the 10 regions operate a fully integrated programme. In the last region - the Northern Region - integration has been slow on account of a poor health inf rastructure, sparse distribution of population over long distances and poor roads. For parts of this region, therefore, some monthly domiciliary service is still administered (Figure 3).

Increasing numbers of cases have been reported by general health workers who were trained in leprosy control.

Following the massive public educational campaigns and the training of health workers in leprosy there has been a significant reduction in the degree of stigma.

Training in leprosy has been incorporated in the curricula of all health training institutions.

\section{Problems}

Like all innovative programmes there are bound to be initial problems. A number of the problems we encountered were minor but I shall highlight the major problems which threatened the programme and the measures which were taken to deal with them:

Some leprosy technical officers felt threatened by the change, and consequently attempted to thwart it. In 1 region, 9 months after a circular had gone round for the establishment of treatment centres at all health facilities, nothing had been done and the programme was still run vertically. A national workshop was organized for all leprosy technical officers at which the important role they would play in the integrated programme was highlighted. Thereafter, they felt less threatened. It was also realized that the system of drug distribution facilitated the running of the programme vertically, and change was required.

To ensure that the technical officers sent returns to District Medical Officers, and not directly to their regional technical officers, as under the vertical programme, drugs were issued from the Regional Medical Stores to the District Medical Officers.

Initially some Regional Directors of Health Services and District Medical Officers failed to come to terms with the new responsibilities that had been devolved to them. Some of them still expected the headquarters of the leprosy service to draw regional action plans on leprosy, monitor district programmes and even discipline staff. However, the regular monitoring of the progress of integration in the regions and the feedback given have largely overcome the problem.

\section{Conclusions}

Several approaches have been adopted towards the integration of leprosy control. The approach was adopted, i.e. the development of the leprosy service at almost the same pace as the development of primary health care has been facilitated by a number of factors. First was the commitment of the ministry towards the strengthening of the 
health service for the effective implementation of primary health care. Second was the incorporation of a regular system of monitoring from the national to the subdistrict levels for the early identification of operational problems. Finally, the donors displayed a great deal of flexibility towards meeting our changing needs during the transition phase.

\section{References}

1 Warndorf DK, Warndorf JA. Leprosy control in Zimbabwe, from a vertical to a horizontal programme. Lepr Rev, 1990; 61: 183-7.

2 Noordeen SK. Elimination of leprosy as a public health problem. Lepr Rev, 1992; 63: 1-4.

3 Management Information System, Ministry of Health Policy Document, Ghana, 1992.

${ }^{4}$ Policy Document on Health Sector Reorganisation in Ghana, Ministry of Health, 1992.

5 Policy Document on Strengthening District Health Systems, Ministry of Health, Ghana. 